\title{
Quality of Life of Patients Before Coronary Artery Bypass Graft Surgery
}

\author{
Kobra Limoee $^{1}$, Shahram Baraz $\mathbb{D D}^{1,{ }^{1},}$, Marziyeh Asadizaker ${ }^{1}$, Amanollah Heidari $^{2}$ and Elham Maraghi $^{3}$ \\ ${ }^{1}$ Nursing Care Research Center in Chronic Diseases, School of Nursing and Midwifery, Ahvaz Jundishapur University of Medical Sciences, Ahvaz, Iran \\ ${ }^{2}$ Department of Cardiac Surgery, Atherosclerosis Research Center, Imam Hospital, Ahvaz Jundishapur University of Medical Sciences, Ahvaz, Iran \\ ${ }^{3}$ Department of Biostatistics and Epidemiology, School of Public Health, Ahvaz Jundishapur University of Medical Sciences, Ahvaz, Iran \\ "Corresponding author: Nursing Care Research Center in Chronic Diseases, School of Nursing and Midwifery, Ahvaz Jundishapur University of Medical Sciences, Ahvaz, Iran. \\ Email: shahrambaraz@ajums.ac.ir
}

Received 2018 September 28; Revised 2018 November 24; Accepted 2018 December 20.

\begin{abstract}
Background: Coronary artery disease (CAD) is the most common chronic disease with marked effects on different health aspects, which can affect the quality of life (QOL) of patients. Today, open heart surgery is one of the most common treatments for patients with CAD.

Objectives: This study was conducted to determine the QOL of patients before coronary artery bypass graft (CABG).

Methods: This descriptive-analytical study was conducted in 2017 - 2018 on 104 candidates for CABG in the Golestan and Imam Khomeini hospitals, affiliated to Jundishapur University of Medical Sciences in Ahvaz. The subjects were selected using the convenience sampling technique. Data collection instruments included a demographic questionnaire and the MacNew quality of life questionnaire. Data was collected on the day before surgery and evaluated with mean, percentage, and frequency in SPSS 22.

Results: Findings showed that the overall QOL score was $87.3 \pm 0.76$. The score mean in the emotional dimension, physical dimension, and social dimension were respectively; $4.01 \pm 0.72,3.25 \pm 0.78$, and $3.45 \pm 0.80$.

Conclusions: Regarding the effect of CAD on QOL of patients, healthcare providers should plan to improve their QOL.
\end{abstract}

Keywords: Quality of Life, Coronary Artery Disease, Coronary Artery Bypass, Health

\section{Background}

Coronary artery disease (CAD) is one of the most important causes of death and disability in both rich and poor countries (1). The number of deaths from CADs will rise from 17 million in 2008 to 25 million in 2030 (2). Coronary artery disease is treated routinely by non-pharmacological methods such as surgery. Patients who do not respond to pharmacotherapy are undergoing coronary artery bypass graft (CABG) (3). CABG is the main treatment for patients with CAD. In 2009, more than 416000 patients were treated for open heart surgery in the United States (4). CABG is a surgical revascularization procedure for patients with coronary artery disease to improve symptoms and survival (5).

Before the surgery, patients experience a lot of physical and psychological problems. The symptoms of disease include chest pain, dyspnea, fatigue, inability to perform exercise and physical activity, fear and anxiety on the outcomes of the surgery, uncertainties, and depression. These factors may exacerbate the symptoms of the current condition and negatively affect the quality of life (QOL) of the patients (1). Angina can reduce QOL in patients with CAD by causing pain, poor health, dysfunction, and reduced ability in self-care (6). It is believed that in addition to disease severity, concomitant diseases such as diabetes, hypertension, and obesity result in reduced QOL in this group of patients (7).

The health-related quality of life, along with therapeutic interventions, gives the highest importance to the feeling of wellbeing and satisfaction with life (8). The World Health Organization (WHO) considers the following four dimensions for QOL:

(A) Physical health that includes pain and discomfort, sleep and rest, and ability to carry out activities of daily living.

(B) Psychological aspect that includes appearance, positive and negative feelings, memory, concentration, and self-esteem.

(C) Social relationships that include sexual activity, social support, and personal relationships.

(D) Social environment that include financial resources, home environment, access to information, participation in social activities, and transportation facilities (3).

In addition, quality of life is a sense of wellbeing, which 
is due to satisfaction or dissatisfaction with different important aspects of an individual's life. Quality of life is identified as an important outcome and response of a patient to the treatment or a specific procedure. In chronic illnesses quality of life provides valuable information regarding the health status of patients and health care delivery for the treatment team (9). Better knowledge regarding changes in QOL may be particularly useful for patients who are determining their long-term health goals (10). HRQoL is a sense of well-being and reflects patient perception of illness and its symptoms (8). Therefore, in order to prevent complications, it is necessary for the healthcare providers to try to improve the quality of life of patients undergoing coronary artery bypass grafting (11). Research on measures of health-related quality-of-life outcomes of patients before CABG surgery and other cardiovascular therapies is growing among scientists (12). Recent studies have shown a significant influence of health related quality of life on long-term consequences. It has been shown that the poor quality of life predicts death and disability in patients with CHD (8). The important component of cost-effectiveness studies and health-technology assessment is assessing the quality of life. The main reason for health care delivery is impairment in patients' health condition and HRQoL (13).

The quality of life of patients before CABG surgery has been reported in previous studies. The results of the Bahramnezhad et al. (14), study, showed that the quality of life in patients before CABG surgery was relatively favorable in $65 \%$ of patients and in $23 \%$ was unfavorable.

According to definition of World Health Organization, QOL is an individual's perception of their position in life in the context of the culture and value systems in which they live with the relation to their goals, expectations, standards, and concerns. Health care providers need to explain QOL results cautiously for patient care due to the fact that they have to prevent aggravations of disease and policy making (15).

\section{Objectives}

Considering the broad concept of QOL and its variability based on multiple physical, psychological, and social factors, as well as climatic and cultural differences, this study was conducted to determine the quality of life of patients before coronary artery bypass graft surgery.

\section{Methods}

In this descriptive-analytical study, all patients older than 18 years who were candidates for CABG in the Golestan and Imam Khomeini hospitals, affiliated to Jundishapur University of Medical Sciences in Ahvaz, between the first of December 2017 and the first of July 2018 were eligible for inclusion. The subjects were selected using the convenience sampling technique. The inclusion criteria included willingness to participate in the study, candidate for $\mathrm{CABG}$, and awareness of time, place, and self. The exclusion criteria included speech and hearing problems, drug abuse, and use of psychotropic drugs, diagnosis of mental disorders such as depression, and concomitant surgeries such as heart valve repair surgery etc.

\subsection{Data Collection Instruments}

Data collection instruments included a demographic questionnaire and translated version of MacNew quality of life questionnaire, which were completed by the patients on the day before surgery. This questionnaire has a two week time frame and contains 27 items with a global scale and three subscales, emotional performance, physical performance, and social performance. In this questionnaire, the domains of emotional, social, and physical performance are assessed by 14, 13, and 5 items, respectively. The items were divided in a way that each one could cover one, two, or all three domains. In this way, the scores for each patient in physical, emotional, and social performance were the means of the scores given to the items in each domain. Each item is answered via a 7-point Likert scale and the subject's answer to each of the seven propositions indicates his/her stance on a continuum from "always" to "never". The highest and lowest scores in each domain are seven and zero indicating high and low QOL, respectively. Moreover, to present the QOL of the patients qualitatively, the mean scores of $5-7,3-5$, and 1 - 3 were considered good, moderate, and poor, respectively (16).

The MacNew quality of life questionnaire is a standard questionnaire whose validity and reliability have been previously evaluated (17). In Iran, the validity and reliability of this tool was evaluated by Asadi-Lari et al. (18), and Rahimi et al. (9).

\subsection{Statistical Analysis}

The collected data was analyzed in SPSS 22, in which the quantitative variables were reported by means and standard deviations and the qualitative variables by percentages.

\subsection{Ethical Considerations}

This study is a part of a thesis project. The study was registered in the Ethics Committee of Ahvaz Jundishapur University of Medical Sciences under the ethical code IR.AJUMS.REC.1396.548. Before completing the questionnaire, informed consent was obtained from the patients and they were assured that the information related to them would remain confidential. 


\section{Results}

Results suggested that the mean (standard deviation) age of the participants was $56.95 \pm 8.18$ (age range $35-70$ years). According to the data, $66.3 \%$ of the participants were male, 33.7\% female, $87.5 \%$ were married, $75 \%$ were illiterate, and 25\% literate. Among the participants, 97.1\% had one, two, and/or all three of the underlying diseases (diabetes, hypertension, and hyperlipidemia). The most prevalent underlying diseases were hyperlipidemia (74\%), hypertension (68.2\%), and diabetes (42.3\%). Family history of heart disease was observed in $72.1 \%$ of the participants, and $44.2 \%$ of them had a history of smoking (Table 1 ).

Research findings regarding the QOL and its three subscales among the participants showed that most of them scored moderately in these indices. Table 2 presents the mean overall score of QOL and its three subscales received by the participants.

\section{Discussion}

Research findings showed that the QOL of the participants was at a moderate level. In this research, results indicated the age of the patients was between 33 and 70 years, thus, it can reinforce the fact that aging plays a role in the increasing incidence of heart disease, and it is also aligned with the study results of Balistreri et al. (19), Asadi-Lari et al. (18), Bahrami-Eyvanekey and Ramezani-Badr (20), and Imanipor et al. (21). Results of this study suggest that CAD and its underlying factors should be considered more carefully when providing this age group with healthcare services to avoid high costs and irreparable complications in future caused by CAD progression.

In the current study, the majority of participants were males. In other studies conducted on patients with CAD, most of the patients were males $(11,22,23)$. Hormonal issues that protect women against cardiovascular disease during childbearing years - for example the possible role of estrogens - could explain their lower incidence the studied sample. Cardiovascular disease in women is generally manifested 10 years later than in men. It is associated with multiple concomitant risk factors (24).

\begin{tabular}{lc}
\hline Table 1. Mean and Standard Deviation of Demographic Quantitative Variables \\
\hline Variable & Mean \pm SD \\
\hline Age & $56.95 \pm 8.18$ \\
Height & $168.29 \pm 9.06$ \\
Weight & $79.68 \pm 13.91$ \\
BMI & $28.14 \pm 4.44$ \\
EF & $47.88 \pm 6.60$ \\
\hline
\end{tabular}

\begin{tabular}{|c|c|}
\hline Variable & No. $(\%)$ \\
\hline \multicolumn{2}{|l|}{ Gender } \\
\hline Female & $35(33.7)$ \\
\hline Male & $69(66.3)$ \\
\hline \multicolumn{2}{|l|}{ Ethnicity } \\
\hline Persian & $66(63.5)$ \\
\hline Arabian & $38(36.5)$ \\
\hline \multicolumn{2}{|l|}{ Marital status } \\
\hline Single & $13(12.5)$ \\
\hline Married & $91(87.5)$ \\
\hline \multicolumn{2}{|l|}{ Educational attainment } \\
\hline Illiterate & $78(75)$ \\
\hline Literate & $26(25)$ \\
\hline \multicolumn{2}{|l|}{ Family history of heart disease } \\
\hline Yes & $75(72.1)$ \\
\hline No & $29(27.9)$ \\
\hline \multicolumn{2}{|l|}{ History of disease } \\
\hline Diabetes & $3(2.82)$ \\
\hline Hypertension & $5(4.8)$ \\
\hline Hyperlipidemia & $22(21.15)$ \\
\hline Hypertension, hyperlipidemia, diabetes & $30(28.84)$ \\
\hline Hypertension and diabetes & $6(5.76)$ \\
\hline Hypertension, hyperlipidemia & $20(19.23)$ \\
\hline Hyperlipidemia, diabetes & $5(4.8)$ \\
\hline No history & $13(12.6)$ \\
\hline
\end{tabular}

In the present research, most of the participants were illiterate (75\%). In the study conducted by Durmaz, the majority of participants had a primary school education (25). In the research that Bahrami-Eyvanekey and RamezaniBadr carried out, $56.2 \%$ of the participants were illiterate (20). It seems that chronic diseases such as CAD are more prevalent among people with a low level of literacy. The literature states that often low literacy level people do not adhere to health recommendations (11). Through making fundamental changes in awareness and attitude, educational attainment has always been effective in health and illness and also in other aspects of life and, in many studies, has received attention as a factor affecting QOL (26). Studies have shown that people with a low level of literacy suffer from a higher degree of anxiety before CABG (27); in addition, anxiety is an important factor in determining the QOL of patients undergoing this surgery (28). In comparison, the predominance of male elderly subjects of low socioeconomic class was similar to that reported by other studies 
carried out in Brazil. This may be representative of the socioeconomic pattern and profile of patients treated in public hospitals insured by the Unified Health System (24).

In the current study, the majority of participants had one, two, or all three of the underlying diseases of CAD (diabetes, hypertension, and hyperlipidemia). Hyperlipidemia, hypertension, and diabetes accounted for $74 \%, 68 \%$, and $42 \%$ of the underlying diseases, respectively. It seems that the patients with hypertension and diabetes received adequate treatment for their underlying diseases and had adjusted themselves to them. However, the participants with hyperlipidemia were not aware of their illness and/or did not receive treatment. Najafi et al. (29), reported that there were no significant relationships between any of the risk factors and QOL. Simpson and Pilote compared the QOL of diabetic and non-diabetic patients after acute myocardial infarction and showed that diabetes was not involved as an independent determining factor for QOL and functional status in these patients (30).

Results showed that the participants obtained an overall QOL score of $3.87 \pm 0.76$, mean emotional performance score of $4.01 \pm 0.72$, mean physical performance score of $3.25 \pm 0.78$, and mean social performance score of $3.45 \pm$ 0.80 . Results also indicated that the overall QOL score and its three subscale scores were at a moderate level, which indicated the effect of CAD on QOL of the participants Table 3. Findings of this study are in consistent with the findings of the study of Bahramnezhad et al.

The results showed that the quality of life in patients before CABG surgery was relatively favorable in $65 \%$ of patients and in $23 \%$ was unfavorable (14). The results of Rahimi et al. showed that the mean score in the emotional dimension physical dimension and social dimension were respectively; $7.66 \pm 10.5,7.76 \pm 76.2$, and $7.65 \pm 72.5$ (9). The results of Dal Boni et al. showed that the mean score in the emotional dimension physical dimension, social dimension, and global QOL were respectively; $5.66 \pm 0.92$, $4.90 \pm 1.35,3.03 \pm 1.91$, and $4.6 \pm 0.12$ (24).

Before coronary artery bypass surgery, assessment of Quality of Life in the physical domain aspect of the generic instrument showed the worst score. This domain assesses mainly daily activities, revealing the major limitation of the patient in these activities as a result of the aging process and its comorbidities and thus, a worse quality of life. A previous study, translated by reports of seniors on lim-

Table 3. Mean (Standard Deviation) of Overall QOL Score and Its Three Subscales for Research Participants

\begin{tabular}{ccccc}
\hline & $\begin{array}{c}\text { Overall } \\
\text { Score }\end{array}$ & $\begin{array}{c}\text { Emotional } \\
\text { Activity }\end{array}$ & $\begin{array}{c}\text { Physical } \\
\text { Activity }\end{array}$ & $\begin{array}{c}\text { Social } \\
\text { Activity }\end{array}$ \\
\hline Mean \pm SD & $3.87 \pm 0.76$ & $4.01 \pm 0.72$ & $3.25 \pm 0.78$ & $3.45 \pm 0.80$ \\
\hline
\end{tabular}

itations in daily activities, inability to work, and to establish social relationships, as well as loss of independence, reported that heart failure is related to impairment of physical functioning performance (11). CAD affects all aspects of health, and patients with this illness have lower QOL compared to people not suffering from it. A large number of factors such as age, gender, educational attainment, underlying disease, history of smoking, family history of heart disease, and many others can affect the QOL of these people. In general, patients with CAD have a moderate level of QOL.

\subsection{Conclusion}

In medical research as well as in studies on public health, QOL is considered a valuable index for measuring health status. Therefore, provision of appropriate and necessary education for these patients must be emphasized to prevent recurrence of this disease in them and to upgrade their health level and QOL. Paying attention to their QOL by nurses directs planning for caregiving, nursing measures, and discharge can be carried out in such a way as to improve the QOA of these patients if nurses pay attention to the QOL of this group of patients.

The limitations of this study were a small number of samples. Therefore, it is suggested that more studies be done with larger sample sizes so that the generalizability of the findings increases.

\section{Acknowledgments}

This article is a part of the master's thesis in internal surgical nursing by Kobra Limoee presented at Jundishapur University of Medical Sciences of Ahvaz.

\section{Footnotes}

Authors' Contribution: Study concept and design: Kobra Limoee, Shahram Baraz, Marzie Asadizaker, and Amanollah Heidari; acquisition of data: Kobra Limoee, Shahram Baraz, Marzie Asadizaker, and Amanollah Heidari; analysis and interpretation of data: Elham Maraghi; drafting of the Manuscript: Kobra Limoee, Shahram Baraz, Marzie Asadizaker and Amanollah Heidari; critical revision of the manuscript for important intellectual content: Kobra Limoee, Shahram Baraz, Marzie Asadizaker and Amanollah Heidari; statistical analysis: Elham Maraghi; administrative, technical, and material support: Kobra Limoee, Shahram Baraz, Marzie Asadizaker and Amanollah Heidari; study supervision: Shahram Baraz.

Conflict of Interests: We have no interests related to the material in the manuscript. 
Ethical Considerations: This study is a part of a thesis project. The study was registered in the Ethics Committee of Ahvaz Jundishapur University of Medical Sciences under the ethical code IR.AJUMS.REC.1396.548.

Funding/Support: This study was supported by Ahvaz Jundishapur University of Medical Sciences, Ahvaz, Iran.

\section{References}

1. Ramesh C, Nayak BS, Pai VB, George A, George LS, Devi ES. Preoperative anxiety in patients undergoing coronary artery bypass graft surgery - A cross-sectional study. Int J Africa Nurs Sci. 2017;7:31-6. doi: 10.1016/j.ijans.2017.06.003.

2. World Health Organization. The global burden of disease. Geneva: WHO; 2008, [cited 2008].

3. Eraballi A, Pradhan B. Quality of life improvement with rehabilitation according to constitution of the World Health Organization for coronary artery bypass graft surgery patients: A descriptive review. Ayu. 2017;38(3-4):102-7. doi: 10.4103/ayu.AYU_152_17. [PubMed: 30254387]. [PubMed Central: PMC6153913].

4. Razmjoee N, Ebadi A, Asadi-Lari M, Hosseini M. Does a "continuous care model" affect the quality of life of patients undergoing coronary artery bypass grafting? J Vasc Nurs. 2017;35(1):21-6. doi: 10.1016/j.jvn.2016.12.002. [PubMed: 28224947].

5. Sekhri T, Kanwar RS, Wilfred R, Chugh P, Chhillar M, Aggarwal R, et al. Prevalence of risk factors for coronary artery disease in an urban Indian population. BMJOpen. 2014;4(12). e005346. doi:10.1136/bmjopen2014-005346. [PubMed: 25488095]. [PubMed Central: PMC4281543].

6. Moattari M, Adib F, Kojuri J, Tabatabaee SH. Angina self-management plan and quality of life, anxiety and depression in post coronary angioplasty patients. Iran Red Crescent Med J. 2014;16(11). e16981. doi: 10.5812/ircmj.16981. [PubMed: 25763214]. [PubMed Central: PMC4329936].

7. Soni RK, Porter AC, Lash JP, Unruh ML. Health-related quality of life in hypertension, chronic kidney disease, and coexistent chronic health conditions. Adv Chronic Kidney Dis. 2010;17(4):e17-26. doi: 10.1053/j.ackd.2010.04.002. [PubMed: 20610351]. [PubMed Central: PMC2901238].

8. De Smedt D, Clays E, Annemans L, Doyle F, Kotseva K, Pajak A, et al. Health related quality of life in coronary patients and its association with their cardiovascular risk profile: Results from the EUROASPIRE III survey. Int J Cardiol. 2013;168(2):898-903. doi: 10.1016/j.ijcard.2012.10.053. [PubMed: 23201081].

9. Rahimi A, Taghipoor H, Ebadi A, Pourebrahimi M. [Comparing Patients' quality of life before and after coronary artery bypass graft surgery]. Iran J Crit Care Nurs. 2014;7(3):194-9. Persian.

10. Erskine NA, Gandek B, Tran HV, Abu H, McManus DD, Kiefe CI, et al. Barriers to healthcare access and to improvements in health-related quality of life after an acute coronary syndrome (from TRACE-CORE). Am J Cardiol. 2018;122(7):1121-7. doi: 10.1016/j.amjcard.2018.06.043. [PubMed: 30107903].

11. Bikmoradi A, Masmouei B, Ghomeisi M, Roshanaei G, Masiello I. Impact of telephone counseling on the quality of life of patients discharged after coronary artery bypass grafts. Patient Educ Couns. 2017;100(12):2290-6. doi: 10.1016/j.pec.2017.06.010. [PubMed: 28625860].

12. Grand N, Bouchet JB, Zufferey P, Beraud AM, Awad S, Sandri F, et al. Quality of life after cardiac operations based on the minimal clinically important difference concept. Ann Thorac Surg. 2018;106(2):54854. doi: 10.1016/j.athoracsur.2018.02.050. [PubMed: 29580777].

13. Cepeda-Valery B, Cheong AP, Lee A, Yan BP. Measuring health related quality of life in coronary heart disease: The importance of feeling well. Int J Cardiol. 2011;149(1):4-9. doi: 10.1016/j.ijcard.2010.09.048. [PubMed: 21035879].
14. Bahramnezhad F, Asadi Noughabi AA, Sief H, Mohammadi Y. [Quality of life in the patients with coronary bypass graft]. Iran J Nurs. 2012;7(26):34-41. Persian.

15. Ogutmen B, Yildirim A, Sever MS, Bozfakioglu S, Ataman R, Erek $\mathrm{E}$, et al. Health-related quality of life after kidney transplantation in comparison intermittent hemodialysis, peritoneal dialysis, and normal controls. Transplant Proc. 2006;38(2):419-21. doi: 10.1016/j.transproceed.2006.01.016. [PubMed:16549136].

16. Friedrich O, Sipotz J, Benzer W, Kunschitz E, Hofer S. The dimensional structure of the MacNew health related quality of life questionnaire: A mokken scale analysis. J Psychosom Res. 2015;79(1):43-8. doi: 10.1016/j.jpsychores.2015.04.007. [PubMed: 25944077].

17. Pavy B, Iliou MC, Hofer S, Verges-Patois B, Corone S, Aeberhard $P$, et al. Validation of the French version of the MacNew heart disease health-related quality of life questionnaire. Arch Cardiovasc Dis. 2015;108(2):107-17. doi: 10.1016/j.acvd.2014.09.006. [PubMed: 25453715].

18. Asadi-Lari M, Javadi HR, Melville M, Oldridge NB, Gray D. Adaptation of the MacNew quality of life questionnaire after myocardial infarction in an Iranian population. Health Qual Life Outcomes. 2003;1(1):23. doi: 10.1186/1477-7525-1-23.

19. Balistreri CR, Madonna R, Melino G, Caruso C. The emerging role of Notch pathway in ageing: Focus on the related mechanisms in age-related diseases. Ageing Res Rev. 2016;29:50-65. doi: 10.1016/j.arr.2016.06.004. [PubMed: 27328278].

20. Bahrami-Eyvanekey Z, Ramezani-Badr F. [Quality of life in patients candidate for coronary artery bypass graft surgery in Zanjan]. Quart J Geriat Nurs. 2018;2(4):95-106. Persian.

21. Imanipor M, Basampor S, Bohrani N. [Relationship between pereoperation variables of coronary artery bypass surgery and time of extubation]. Hayat. 2006;12(1):5-16. Persian.

22. Dantas RA, Motzer SA, Ciol MA. The relationship between quality of life, sense of coherence and self-esteem in persons after coronary artery bypass graft surgery. Int J Nurs Stud. 2002;39(7):745-55. doi: 10.1016/S0020-7489(02)00017-2. [PubMed:12231031].

23. Hasani MR, Farahani B, Zohour AR, Panahi AS. [Self-care ability based on Orem's theory in individuals with coronary artery disease]. Iran J Crit Care Nurs. 2010;3(2):87-91. Persian.

24. Dal Boni ALM, Martinez JE, Saccomann ICRS. [Quality of life of patients undergoing coronary artery bypass grafting]. Acta Paulista de Enfermagem. 2013;26(6):575-80. Portuguese. doi: 10.1590/s010321002013000600011.

25. Durmaz T, Özdemİr O, Akyunak Özdemİr B, Kele T, Akar Bayram N, Bozkurt E. Factors affecting quality of life in patients with coronary heart disease. Turk J Med Sci. 2009;39(3):343-51.

26. Pournaghash-Tehrani S, Etemadi S. ED and quality of life in CABG patients: An intervention study using PRECEDE-PROCEED educational program. Int J Impot Res. 2014;26(1):16-9. doi: 10.1038/ijir.2013.27. [PubMed: 23759828].

27. Korbmacher B, Ulbrich S, Dalyanoglu H, Lichtenberg A, Schipke JD, Franz M, et al. Perioperative and long-term development of anxiety and depression in CABG patients. Thorac Cardiovasc Surg. 2013;61(8):676-81. doi: 10.1055/s-0032-1333326. [PubMed: 23344765].

28. Kidd T, Poole L, Leigh E, Ronaldson A, Jahangiri M, Steptoe A. Attachment anxiety predicts IL-6 and length of hospital stay in coronary artery bypass graft surgery (CABG) patients. $J$ Psychosom Res. 2014;77(2):155-7. doi: 10.1016/j.jpsychores.2014.06.002. [PubMed: 25077858]. [PubMed Central: PMC4121675].

29. Najafi SM, Vahedparast H, Hafezi S, Saghafi A, Farsi Z, Vahabi Y. [Effect of self-care education on quality of life in patients suffering from myocardial infarction]. Iran J Crit Care Nurs. 2008;1(1):35-9. Persian.

30. Simpson E, Pilote L. Quality of life after acute myocardial infarction: A comparison of diabetic versus non-diabetic acute myocardial infarction patients in Quebec acute care hospitals. Health Qual Life Outcomes. 2005;3:80. doi: 10.1186/1477-7525-3-80. [PubMed: 16329755]. [PubMed Central: PMC1327687]. 